\title{
Physics in Carnacki's investigations: The role of new scientific discoveries in literature
}

\author{
Amelia Carolina Sparavigna \\ Department of Applied Science and Technology, Politecnico di Torino, Torino, Italy \\ Email address: \\ amelia.sparavigna@polito.it
}

\section{To cite this article:}

Amelia Carolina Sparavigna. Physics in Carnacki's Investigations: the Role of New Scientific Discoveries in Literature. International Journal of Literature and Arts. Vol. 1, No. 1, 2013, pp. 11-15. doi: 10.11648/j.ijla.20130101.13

\begin{abstract}
In the stories of Carnacki, a fictional supernatural detective created by the English writer William H. Hodgson, and written between 1910 and 1913, we can find an interesting mixture of science and fantasy. Carnacki is a ghost finder, who investigates in an environment where supernatural is occurring. However, we find that he is using scientific discoveries and technologies of the beginning of the 20th century to reveal the hidden clues leading to the solution of the mysteries. Therefore, bringing the modern science into the fiction, Carnacki's investigations are mirroring some of the popular knowledge of physics and technology of that time.
\end{abstract}

Keywords: English Literature, History of Science

\section{Introduction}

Thomas Carnacki is a fictional detective, who investigates mysteries with can have a possible supernatural origin, created by William Hope Hodgson (1877-1918), an English writer. Carnacki, the Ghost Finder, is the protagonist of short stories, some published between 1910 and 1913 and a few of them posthumously [1]. As the other famous fictional detective Sherlock Holmes, Carnacki lives as a bachelor in Chelsea, London. Like in the Sir Arthur Conan Doyle's stories, where Dr. Watson is reporting the adventures of Sherlock Holmes, it is Dodgson, one of Carnacki's four friends, who, in a first-person perspective, is reporting the adventures. "In response to Carnacki's usual card of invitation to have dinner and listen to a story", the five friends meet at 427 , Cheyne Walk, and after dinner they are merged in the Carnacki's tales of supernatural adventures.

When Carnacki is called for help when haunting is suspected, he uses some traditional tools such as chalk, water and candles, drawing the pentacles in old rituals for protection. However, Carnacki is inventing an electric pentacle, using the new technologies of the early 20th century, as an improved device. The sensitivity of photographic plates is also used, to discover the presence of invisible things. Unlike the Sherlock Holmes's character, the Carnacki's scientific background is never disclosed in detail by the writer, but it is clear that he knew physics and chemistry.

The character of Carnacki was probably inspired by Doctor Hesselius [2], a scientist investigating the supernatural, protagonist of some short stories written by Joseph Sheridan Le Fanu. And the Hodgson's works probably influenced some later writers, such as Seabury Quinn who created the supernatural detective Jules de Grandin [3].

The nature of this Hodgson's creation is that of an English gentleman, never exceeding the story frame. Being the Carnacki's character not dogmatic, he always tries to find some clues to reach a conclusion. In some stories, the haunting is real, while in others, the problem is not solved clearly: therefore, the reader is never sure if ghosts existed or not. What is fascinating in the stories of this Ghost Finder is then the environment, where supernatural is possible but not certainly stated.

Moreover, the presence of science in an intriguing mixture with fantasy deserves to be analysed, because the Carnacki's stories can show quite well some of the popular knowledge of physics and technology at the beginning of the 20 th century.

\section{Electricity, Optics and Vibrations}

As told before, Hodgson was able to create an intriguing suspense between haunting and real facts. In "The Gateway of the Monster", 1910 [4], Carnacki is hired by a gentleman 
to investigate a noisy spirit spending each night slamming the door of a room in the manor house. This is the first investigation during which Carnacki uses the electric pentacle to protect himself while spending the nights in that room. He succeeds in trapping the haunting entity inside this pentacle.

In "The House among the Laurels", 1910 [5], a deserted mansion displays signs of haunting. However, Carnacki discovers by means of a camera and analysing the photographic plates, that a criminal gang is actually living hidden in the mansion, taking advantages of frightening people with haunting tricks.

In "The Thing Invisible", 1912 [6], Carnacki is using a camera to capture any mysterious phenomena in the dark of a chapel of an Edwardian manor house. In this chapel, an old haunted dagger is kept, which is believed to attack any enemy who should dare to venture into the Chapel after the sunset. In the dark of the night, Carnacki hears mysterious noises and when he approaches the altar, the dagger nearly kills him. However, the photographic evidence shows the truth: subtle differences between photographic plates reveal the mechanism of an ancient trap armed to guard the altar.

In "The Hog", published posthumously in 1947, Carnacki faces a disturbing giant hog spirit that is trying to enter the real world from horrifying nightmares. He is equipped with a new variant on the electric pentacle, a device able to record the nightmares when put to the head of a dreamer. In this story, Carnacki reproduces the nightmares, recorded on a paper band, in the form of sounds.

In "The Haunted Jarvee", published posthumously in 1929, we find a device to create vibrations. In the story, Carnacki decides to go aboard the Jarvee, an antique sailing ship, to investigate a possible haunting. In the night, some shadows are appearing on the surface of the sea, running like waves towards the ship. Close to the Jarvee, they disappear from sight. After a while, a furious storm arises which elapses all the night. Carnacki guesses that the phenomenon is caused by some vibrations and develops a device to emit repellent vibrations. After some good results, the machine is not able to suppress more furiously raging storms, and, at the end, Carnacki and the crew are forced to abandon the Jarvee that sinks in the ocean. Dodgson asks what caused the haunting and Carnacki explains his theory on "focuses", saying that the Jarvee was a sort of focal point for vibrations. Carnacki replied that in his opinion "she was a focus. That is a technical term which I can best explain by saying that she possessed the 'attractive vibration' that is the power to draw to her any psychic waves in the vicinity, much in the way of a medium. The way in which the 'vibration' is acquired - to use a technical term again - is, of course, purely a matter for supposition." [7]

The explanation has its framework in the theories about the spiritual vibrations, connected to the Spiritualism, where the mediums are focusing elements. The Spiritualism was a religious movement that began in the United States and was prominent between 1840s and 1920s in
English-speaking countries. Its distinguishing belief is that some spirits of dead people live a higher level of existence, but they are able to become spiritual guides when the Mediums are able to establish a relationship. In the case of the English naturalist Alfred R. Wallace [8] and of Sir Willian Croockes, chemist and physicist, Spiritualism was a matter of science, not only a religious belief. We can imagine then that Hodgson knew the book on the phenomena of Spiritualism written by Crookes in 1904 [9]. However, to tell the true, the Jarvee seems the receiver of a wireless station. Let us remember that Guglielmo Marconi made the first experiment of a transatlantic wireless communication in 1901 .

"The Hog" and "The Haunted Jarvee" were published posthumously, after the dead of Hodgson in 1918. Here we prefer considering only the stories published between 1910 and 1913, at the beginning of the century then, and discuss the links to the new science that we can find in them. Let us tell just this, that in "the Haunted Jarvee" we have a very impressive description of St. Elmo's Fires, the electrical phenomenon in which luminescent plasma is created by a corona discharge at the ship's masts, due to atmospheric electric field.

\section{Glowing Gases}

The "electric pentacle" is a device invented by Hodgson for his character as a protection against supernatural forces, ghosts or monsters. The device consists of a set of wires and glowing vacuum tubes, and, actually, it turns out to be a portrait of the electric technology of the early 20th century. Hodgson describes the elaborate set-up, which Carnacki prepared, besides the traditional pentacles, for protection during the nights spent in a haunted room. Carnacki created this technological device, after becoming aware of some experiments, that is, after reading the book 'Experiments with a Medium' written by the Professor Garder. Carnacki tells: "When they surrounded the Medium with a current, in vacuum, he lost his power - almost as if it cut him off from the Immaterial. That made me think a lot; and that is how I came to make the Electric Pentacle, which is a most marvelous 'Defense' against certain manifestations. I used the shape of the defensive star for this protection, because I have, personally, no doubt at all but that there is some extraordinary virtue in the old magic figure. Curious thing for a Twentieth Century man to admit, is it not? ... I turned now to fit the Electric Pentacle, setting it so that each of its 'points' and 'vales' coincided exactly with the 'points' and 'vales' of the drawn pentagram upon the floor. Then I connected up the battery, and the next instant the pale blue glare from the intertwining vacuum tubes shone out" [4]. The same device used in "The Gateway of the Monster" is described in "The House among the Laurels": the pentacle, when connected up the batteries, shines a weak blue glare from vacuum tubes.

Carnacki tells that he had the idea of an electric pentacle after reading of Garder's experiments. Of course, this 
publication written by Garder as author is fictional and does not exist, but we can suppose that similar experiments with glowing tubes could have been performed at the beginning of 20th century, and reported in the magazines. Let us note that Sir Crookes dealt with several famous spiritual mediums and this could have inspired the figure of a scientist investigating the supernatural. Actually, Sir Crookes made the first experimental observations of new phenomena concerning the electrical discharge in low-pressure gases in 1898 [10]. This was the first steps of the plasma science. In fact, Reference 11 is suggesting that the use of the word "plasma" was related to the Spiritualism.

We can imagine Carnacki's electric pentacle made as a neon luminous tube sign, containing neon or other inert gases at a low pressure. A high voltage applied to electrodes makes the gas glow brightly. The neon sign is an evolution of the earlier glass tubes for demonstrating the principles of electrical discharge in gases. But, were neon signs existing in 1910? The answer is positive. The Nikola Tesla's neon lamp signs were firstly shown during the 1893 Chicago World's Fair [12,13]. Later, in 1897, D. McFarlan Moore gave a demonstration of his results in developing new glowing lamps [14], producing "the daylight in a tube" and disclosing a lighting system never seen before. Georges Claude, French engineer and inventor, displayed the first large neon sign in the December of 1910, at the Paris Motor Show. First commercial signs were sold in 1912 [13].

Hodgson, as his electric pentacle demonstrates, knew this technological application of the studies on glowing discharges in low-pressure gases. However, he used much more knowledge of physics in his tales: we will see this in the following sections.

\section{Carnacki and the "Lightless" Photography}

As we have reported before, Carnacki uses photography in almost all of his adventures. As in "The Horse of the Invisible", 1910 [15], Carnacki performs experimental photographs of a subject and her/his surrounding, because "sometimes the camera sees things that would seem very strange to normal human eyesight... I asked Miss Hisgins to join me in my experiments. She seemed glad to do this and I spent several hours with her, wandering all over the house, from room to room and whenever the impulse came I took a flashlight of her and the room or corridor in which we chanced to be at the moment." [15] Carnacki hoped that the sensitivity of photographic plates could reveal an invisible presence near the subject. This is, more or less, an approach commonly believed to reveal supernatural spirits.

When Hodgson was writing the adventures of Carnacki, long time had passed from the first permanent photograph image produced in 1826 by Nicéphore Niépce, French inventor. The "Boulevard du Temple", taken by Louis Daguerre in 1838 or 1839 , can be considered the first known picture of a person. The subject was a boulevard but since exposure time was of about ten minutes, moving people and traffic do not appear. Just a man was recorded in a corner of the image frame, because he stood still while getting his boots polished. In 1839, Daguerre announced the development of the process for daguerreotypes. In fact, in 1832, Hercules Florence had already created a very similar process, naming it 'Photographie' [16].

The modern photographic process was obtained after a series of refinements and improvements: let us just remember George Eastman. In July of 1888 Eastman's Kodak camera went on the market turning the image recording in a popular resource, and finally in 1901 reached the mass-market with the Kodak Brownie camera. Hodgson was fond of photography and often illustrated his lectures with colour slides (see the Appendix on Hodgson's life).

We can consider the photography as a well-known technology in 1910 and then it is natural for the Hodgson's character to use it, but Carnacki is surprising. In the story "The Thing Invisible" of 1912, he claims his interest in the "lightless photography". "I set to work immediately to develop, not the plate I had exposed, but the one that had been in the camera during all the time of waiting in the darkness. ... You all know something of my experiments in lightless photography, that is 'lightless' so far as our human eyes are capable of appreciating light? It was X-ray work that started me in that direction, and now I had vague and indefinite hopes that, if anything immaterial had been moving in the chapel the camera might have recorded it." This quotation about X-rays is rather interesting. Let us report in the next section a short history of X-rays where we shall see the connection with photography, in particular with the 'lightless' photography.

\section{From Crookes to X-Rays}

Let us go back to discuss the electric currents in gases at low pressure. In 1879, during a lecture delivered to the British Association for the Advancement of Science at Sheffield, William Crookes discussed his experiments with a glass cylinder, mostly evacuated, containing electrodes for the discharges of a high voltage electric current (that is, a Crookes tube). He reported that the walls of the tube are emitting a dull blue color and that when unexposed photographic plates are placed near the tube, some of them are showing shadows. We know that are the low-energy $\mathrm{X}$-rays, which are producing this blue glow when hitting the glass.

In his paper of 1891 [17], Crookes refers to Puluj. Ten years before, Ivan Puluj invented a device for producing what he called "cold light" and used it for a kind of X-ray photography. These X-ray emitting devices became the "Puluj lamps", produced for a certain period [18]. Puluj published his results in a paper entitled "Luminous Electrical Matter and the Fourth State of Matter" in the Notes of the Austrian Imperial Academy of Sciences (1880-1883) [19]. Let us note that this is the terminology of 
the plasma physics. According to [18], the paper was rather obscure and this fact could explain the disappointment of Crookes who disagreed with Puluj on the nature of radiant matter.

We guess that Hodgson, during his studies in Liverpool to receive the mate certificate, had the possibility to discuss about the new developments of physics and technology. From his studies and some readings in science divulgation magazines or even scientific journals, he probably gained some knowledge of the problems concerning X-rays and radiant matter.

In that period, there was a strong scientific debate about the radiant state of matter. As Michael Faraday (1791 1867, English scientist who contributed to electromagnetism and electrochemistry) proposed, the matter was classified in four states: solid, liquid, gas and radiant [11]. Researches on the last form of matter started with the studies of Heinrich Geissler (1814-1879): the new discovered phenomena, different from anything previously observed, persuaded the scientists that they were facing with matter in a different state [20]. Crookes took again the term "radiant matter" coined by Faraday: in Ref.17, it is clearly stated than the radiant matter is connected with the residual molecules of gas in the tube.

In April 1887, Nikola Tesla began to investigate X-rays using high voltages and tubes of his own design, as well as Crookes tubes. After several experiments, in 1897 during a lecture before the New York Academy of Sciences [21], Tesla stated the method of construction and safe operation of X-ray equipments, due to the biological hazards associated with X-ray exposure [22].

Wilhelm C. Röntgen was the first to perform a systematic study of X-rays and to recognise them as a new kind and unknown type of radiation, referring to it as " $\mathrm{X}$ ". For this discovery, Röntgen receives the first Nobel Prize in Physics. In 1896. Rontgen gave a demonstration of the medical use of X-ray after he saw a picture of his wife's hand on a photographic plate. It was the first radiograph. In the same period, Thomas Edison invented the fluoroscope that immediately became a standard device for medical X-ray exams [23]. The connection of X-rays and photography, as "lightless photography", is then quite clear.

Let us remember Fernando Sanford too, and his experiences with photography [24], because he did several experiments with X-rays. Previously in 1893, in a letter to The Physical Review [25], he described the discovery of the "electric photography". It is a contact-print photography, and if we see the image of a coin obtained by Sanford in [25], we immediately acknowledge the similarity with Kirlian images. The Kirlian photography refers to a contact photography associated with high voltage, named after Semyon Kirlian, who discovered it in 1939. If an object on a photographic plate is connected to a high voltage source, the corona discharges created by the field at the object edges produce an image on the plate. Sanford wrote also an article entitled "Without Lens or Light, Photographs Taken
With Plate and Object in Darkness", published in the San Francisco Examiner [26].

Before the 20th century, and for a short period after, the $\mathrm{X}$-rays were generated in cold cathode tubes. The tubes contained a small quantity of gas, to allow a current to flow. In 1904, John A. Fleming invented the thermionic diode valve, where heated cathode allows a current in the vacuum, due to a thermionic emission of carriers. The principle was applied to X-ray tubes immediately: we could consider this as the starting point of the modern X-ray technology. Two years later, Charles Barkla (Nobel Laureate in 1917) discovered that X-rays could be scattered by gases, and that each element had a characteristic X-ray. Max von Laue, Paul Knipping and Walter Friedrich observed for the first time the diffraction of X-rays by crystals in 1912. This discovery gave birth to the field of X-ray crystallography. Many other scientists concurred in the development of $\mathrm{X}$-ray technology and its medical use, in some cases injured by the dangerous radiation.

\section{Conclusions}

In this short discussion of the Hodgson's knowledge of physics, which we deduced from Carnacki's stories, we have also reported a small part of the strong debate about the four states of matter at the end of 19th century. We can imagine echoes of this debate on journals and popular magazines and, at the same time, the spreading all over the world of new electric technologies. In conclusion, Hodgson had a solid scientific background from schools probably, reinforced by a true love for science, demonstrated by his experiences in photography of natural phenomena. His main feature can be described by the Carnacki's words, "I ask questions, and keep my eyes open".

\section{Appendix on Hodgson's Life}

Hodgson was born in 1877 in Blackmore End, Essex [27]. At the age of thirteen, Hodgson ran away from school in an effort to become a sailor. Caught, he returned to his family but eventually received his father's permission to begin an apprenticeship as a cabin boy in 1891. After his apprenticeship ended in 1895, Hodgson studied in Liverpool and received the mate certificate. He was then sailor for several years. At sea, Hodgson experienced bullying [28]; the theme of bullying and revenge appeared frequently in his sea stories. The motivation of self-defence induced him in training his body. In addition to exercises with weights and punching bag, Hodgson practiced photography, taking, among others, photographs of atmospheric phenomena such as cyclones, lightning and aurora borealis. During the period as a sailor, he was awarded the Royal Humane Society Medal for heroism. Back from sailing, he opened in 1899 a school of physical culture, in Blackburn, England, offering personal training. In this period he began writing articles on physical culture, featuring photographs of himself while demonstrates exercises. After these articles, Hodgson turned 
his attention to fiction, publishing his first short stories. Moreover, he began to give paid lectures illustrated with colour slides, about his life as a sailor. He wrote poems too, many published posthumously by his widow. Sea stories were sold to American and British magazines: in 1907 he published "The Voice in the Night", a horror sea story, and "The House on the Borderland". In 1909, Hodgson published "Out of the Storm", horror story about "the death-side of the sea", and the novel "The Ghost Pirates".

Hodgson's most famous short sea story is "The Voice in the Night", adapted for two movies. In spite of the fact that these novels received a critical success, the author remained relatively poor. To increase his income, he began working on the first of his recurring characters, Carnacki, featured in his most famous stories. The first of these, "The Gateway of the Monster", was published in 1910 in The Idler. Another recurring character is Captain Gault, a sea captain for hire. In 1912, Hodgson married Betty Farnworth, a staff member of a magazine. After a honeymoon in the south of France, they took up residence there. Returned to England with his wife, he became Lieutenant of the Royal Artillery. In 1916, he suffered injuries from an accident, and discharged from the army, he returned to writing. Sufficiently recovered, he was re-enlisted. He wrote articles and stories reporting his experience during the war. An artillery shell at Ypres killed him in April of 1918. His widow worked to keep his books in print and, after her death in 1943, Hodgson's sister took over his literary legacy

\section{References}

[1] W.H. Hodgson, The Complete Stories of Carnacki the Ghost-Finder, Universal Tandem Publishing Co., Great Britain, 1974.

[2] S. Le Fanu, In a Glass Darkly, Oxford World's Classics, 1993.

[3] S. Quinn, The Casebook of Jules De Grandin, Paperback Popular Library, 1976.

[4] W.H. Hodgson, The Gateway of the Monster, The Idler, January 1910.

[5] W.H. Hodgson, The House among the Laurels, The Idler, February 1910.

[6] W.H. Hodgson, The Thing Invisible, The New Magazine, January 1912.

[7] W.H. Hodgson, The Haunted Jarvee, available at http://ebooks.ebookmall.com/title/haunted-jarveehodgson-e books.htm

[8] A.R. Wallace, The Scientific Aspect of the Supernatural, www.wku.edu/ $\sim$ smithch/wallace/S118A.htm, 1866.
[9] Sir William Crookes, Researches into the Phenomena of Spiritualism, Two Worlds Publishing Company Ltd., 1904.

[10] J. Reece Roth, Industrial Plasma Engineering: Principles, IOP, Bristol, 1995.

[11] M.J. Pinheiro, Plasma: the Genesis of the Word, arxiv:0703260v1, 2007.

[12] N. Tesla, On Light and Other High Frequency Phenomena, Lecture before the Franklin Institute, Philadelphia, 1893, reproduced in the Twenty First Century Books, 2007.

[13] S. van Dulken, Inventing the $20^{\text {th }}$-Century: 100 Inventions that Shaped the World. New York University Press, 2002.

[14] Daylight Seen in Tubes: McFarlan Moore Publicly Demonstrates, The New York Times, May 28, 1897.

[15] W.H. Hodgson, The Horse of the Invisible, The Idler, April 1910.

[16] For more details on the history of photography or X-rays, see Wikipedia.

[17] W. Crookes, Electricity in Transit from Plenum to Vacuum, Scientific American Supplement, No. 795, March 28, 1891, p.4.

[18] A Puluj Lamp is shown at the web page http://www.uibk.ac.at/exphys/museum/en/details/tubes/puluj .html

[19] D. Kulynyak, Noteworthy Ukrainians, Ivan Pului, the Discoverer of X-rays, available at the web page www.ukrweekly.com/Archive/2000/280012.shtml

[20] W. Crookes, Experiments on the Dark Space in Vacuum tubes, Proc. Roy. Soc. London, vol. 79, n.528, pp:98-117, 1907.

[21] N. Tesla: Lecture at New York Academy of Sciences, April 6, 1897, at www.tfcbooks.com $/$ mall $/$ more $/ 351 \mathrm{ntl} . \mathrm{htm}$

[22] M. Cheney, R. Uth and J. Glenn, Tesla, Master of Lightning, Barnes \& Noble Publishing, 1999.

[23] An interesting collection is shown at the site http://www.emory.edu/X-RAYS/century.htm.

[24] F. Sanford, On an Undescribed Form of Radiation, Phys. Rev. I, vol. 17, pp:441-459, 1903.

[25] F. Sanford, Some Experiments in Electric Photography, Phys. Rev. I, vol. 2, n.1, pp:59-61, 1894.

[26] T. Wyman, Fernando Sanford and the Discovery of X-rays, Imprint from the Associates of the Stanford University Libraries. pp. 5-15, 2005.

[27] The appendix is a short abstract for reader's convenience of the item of Wikipedia on William Hope Hodgson.

[28] S. Moskowitz, William Hope Hodgson. West Kingston, 1975. 